\title{
Nutritional Status and Physical Activity of Patients With Knee Osteoarthritis Referred to Hospitals Affiliated to the Ahvaz Jundishapur University of Medical Sciences
}

\author{
Maryam Agha Amiri ${ }^{1, *}$; Abdol Hassan Doulah ${ }^{1}$; Afsaneh Alivand ${ }^{1}$ \\ ${ }^{1}$ Department of Nursing, Faculty of Nursing and Midwifery, Ahvaz Branch, Islamic Azad University, Ahvaz, IR Iran \\ ${ }^{*}$ Corresponding author: Maryam Agha Amiri, Department of Nursing, Faculty of Nursing and Midwifery, Ahvaz Branch, Islamic Azad University, Ahvaz, IR Iran. Tel: +98-9163088656, \\ Fax:+98-6133348351, E-mail: Amiri.mana@yahoo.comdoolahh@yahoo.com
}

Received: November 12, 2014; Revised: April 19, 2015; Accepted: May 3, 2015

\begin{abstract}
Background: Osteoarthritis (OA) is the most common joint disorder with symptoms found in hands, knees, hips, back and neck.
Objectives: This study aimed to evaluate the correlation between nutritional status and physical activity with osteoarthritis of the knee in patients referred to hospitals affiliated with the Ahvaz Jundishapur University of Medical Sciences.

Patients and Methods: The current cross-sectional research was done on 200 people selected by easy sampling and random counting, and included a group of patients and a group of healthy subjects, who served as controls (100 subjects in each group). Data were gathered by a self-made questionnaire. The data were analyzed using the chi-squared and Fisher and Mann-Whitney tests.

Results: The results showed that the majority of subjects in both groups were in the age group of over 64 years. The majority of individuals in the patient group were females. The majority of subjects in the patient group commonly consumed foods from the bread and cereal group while the healthy group consumed foods from the meat and beans group. This difference was statistically significant $(\mathrm{P}<0.001)$. Most individuals within the patient group used less vegetables and salads, had lighter activities in the present and in the past and had never exercised $(\mathrm{P}<0.001)$.

Conclusions: In our study we found a relationship between nutritional status and physical activity in patients with knee osteoarthritis. Therefore, osteoarthritis can probably be prevented if preventive measures are taken at an earlier age.
\end{abstract}

Keywords: Nutritional Status; Physical Activity; Knee Osteoarthritis

\section{Background}

Osteoarthritis (OA) is a chronic degenerative disease of the joints. It is a common kind of arthritis. Osteoarthritis progresses slowly with usual signs and symptoms being pain enlarged and deformed joints as well as limitation of the range of movement. It is a leading cause of disability affecting 60 - 70 percent of the population aged more than 60 years. It generally affects the hands and often the knees and the hip (1). Pain from osteoarthritis is the key symptom, which leads to the decision to seek medical care and is an important antecedent to disability (2). Because of its high prevalence and the frequent disability that accompanies this disease in major joints such as the knees, osteoarthritis accounts for the greatest difficulty with climbing stairs and walking than any other disease (3). This disease is also the most common reason for total hip and total knee replacement (4). The rapid increase in the prevalence of this already common disease suggests that osteoarthritis will have a growing impact on health care and public health systems in the future (5). The worldwide prevalence of symptomatic osteoarthritis is $18 \%$ among women and $9.6 \%$ among men (6). Osteoarthritis is the fourth leading cause of years lived with disability. It accounts for the decrease in activities of daily life in elderly dependent population of the world (7). Certainly the risk factors in high-risk populations include old age, female gender, being overweight, and history of previous injuries (8-10). Osteoarthritis (OA) is a multi-factorial disease with both genetic and environmental determinants (9).

The literature review revealed that the growing epidemic of chronic disease afflicting both developed and developing countries was related to dietary and lifestyle changes and undertook the task of reviewing considerable scientific progress that has been made in different areas. For example, there is better epidemiological evidence for determination of certain risk factors, and the results of a number of new controlled clinical trials are now available (11).

Changes in diets and lifestyles that have occurred with industrialization, urbanization, economic development and market globalization have accelerated over the past decade. This has had a significant impact on the health and nutritional status of populations in developing

Copyright (C) 2015, Ahvaz Jundishapur University of Medical Sciences. This is an open-access article distributed under the terms of the Creative Commons Attribution-NonCommercial 4.0 International License (http://creativecommons.org/licenses/by-nc/4.0/) which permits copy and redistribute the material just in noncommercial usages, provided the original work is properly cited. 
countries and in countries in transition. Because of these changes in diet, chronic diseases are becoming increasingly significant causes of disability and premature death in developing and newly developed countries, placing additional burdens on already overtaxed national health budgets. Energy expenditure through physical activity is an important part of the energy balance equation that determines body weight. A decrease in energy expenditure through decreased physical activity is likely to be one of the major parameters contributing to the global epidemic of obesity. Physical activity has great influence on body composition and the amount of fat (11).

Age is a one of the strongest risk factors for osteoarthritis of all joints $(5,12)$. The increase in the prevalence and incidence of osteoarthritis with age is probably a consequence of cumulative exposure to various risk factors and biological changes that occur with aging. Females are not only more likely to have osteoarthritis, than males, they also have more severe osteoarthritis (13). Dietary factors are the subject of considerable interest in osteoarthritis, however results of studies are conflicting. One of the most promising nutritional factors for osteoarthritis is vitamin D. Without sufficient amounts of vitamin D bones can become thin, brittle or misshapen. In the study of McAlindon et al. subjects in the lowest (< $27 \mathrm{ng} / \mathrm{mL})$ and middle $(27.0$ - $33.0 \mathrm{ng} / \mathrm{mL})$ tertile of serum 25-hydroxyvitamin D were at three-fold higher risk of progressive knee osteoarthritis compared with those in the highest tertile; however, no such effect was observed for risk of incidence of this disease (14).

Numerous studies have shown that knee injury is one of the strongest risk factors of OA. Severe injury to the structures of a joint, particularly a trans-articular fracture, meniscal tear requiring meniscectomy or anterior cruciate ligament injury, could result in an increased risk of osteoarthritis development and musculoskeletal symptomatology $(15,16)$. Studies examining the relationship between sports activities and subsequent osteoarthritis have produced conflicting results. There is some evidence that elite long distance runners are at high risk for the development of knee and hip osteoarthritis (17); and elite soccer players are at higher risk of knee osteoarthritis when compared with non-soccer players (18). Surprisingly, the general level of physical activity itself may also increase the risk of osteoarthritis. For example, physical activity among elderly individuals in the study of McAlindon et al. was generally characterized by leisure time, walking and gardening (19).

\section{Objectives}

The relationship between OA and nutritional status, and physical activity has not been studied extensively in population-based studies especially in Ahvaz. The OA prevalence and the pattern of the disease vary depending on the geographical distribution, which in turn can provide valuable clues about the potential etiological factors. For this reason, we decided to study the correlation between nutritional status and physical activity in patients with chronic knee osteoarthritis who had been referred to hospitals affiliated with the Ahvaz Jundishapur University of Medical Sciences.

\section{Patients and Methods}

In this cross-sectional study, male and female patients referred to the rheumatology clinics of hospitals affiliated with Ahvaz Jundishapur University of Medical Sciences, were investigated. The patients were selected by simple random sampling. The inclusion criteria were: 1 . Having knee osteoarthritis diagnosed by a specialist physician. 2. Willingness to participate in the research and being able to answer questions. After selection of subjects by the mentioned method, they were divided to two groups including patients (100 individuals) and healthy subjects (100 individuals). Physical activity was assessed using a questionnaire $(20,21)$ and nutritional status was based on the Brown technique (22). Questions about dietary habits and nutrition assessed the consumption of supplements, vitamins, salads and vegetables, as well as appetite, and regarding physical activity, questions assessed the type of physical activity, mobility, walking, and professional exercise in the past and present. For validity of the questionnaire the content validity method was used, while two rheumatology specialists approved the validity of the questionnaire. In this research, for reliability of the questionnaire the retest method was used. To do this, one-tenth of the samples were selected from healthy and patient groups, and were asked to respond to the questions. Then, after seven to ten days, the same people were asked to complete the questionnaire again. By using Pearson's correlation coefficient, the average coefficient of reliability (85\%) was used for rating the questions and also, Kappa coefficient (80\%) was used for nominal variables. McNemar's statistical test was used for dual-status variables. On this basis, answers of dual-status questions had not significant changes $(P>0.3)$. Descriptive and inferential statistical methods (SPSS) were used for statistical analysis. In inferential statistics, chi-squared and Fisher tests were used. To compare the age distribution, daily food intake, appetite, and activity, walking and professional exercise in the past between the two groups (healthy and patient) the Mann-Whitney test was used. To compare gender, consumed food groups, special diet, consumption of vitamin supplements in the two groups chi-squared test was used.

This research was done on 200 subjects suffering from osteoarthritis by easy sampling and random counting in two multitudes of patient and healthy subjects (100 cases in each group).

\section{Results}

This research showed that the mean age of subjects in the patient and healthy groups were 61.3 and 59.5, respec- 
tively. The majority of subjects in both groups were in the age group of over 64 years. The majority of individuals in the patients group were females.

Amongst the patient group those who had two meals or less were more than the healthy group, and there were no significant differences between patient and healthy groups. Also the majority of subjects in the patient group consumed more food from the bread and cereal group while in the healthy group meat and beans were more commonly consumed. This difference was statistically significant $(\mathrm{P}<0.001)$.

Most of the patient group did not use any vitamin supplements and used less vegetables and salads $(\mathrm{P}<$ 0.001). Most individuals in the patient group had been heavy physical activity to compare with the healthy group in the past. This difference was statistically sig- nificant $(\mathrm{P}<0.001)$. This also indicates that individuals in the patient group perform lighter activities in the present than in the past. This study indicated that most subjects did not walk or did it irregularly in the past. The majority of subjects in the patient group had never exercised in the past, and the few patients who did professional sports had done weightlifting and football (Tables 1 and 2).

Table 1. Distribution of Absolute and Relative Frequency of Subjects on the Basis of Gender $(2013-2014)^{a}$

\begin{tabular}{lcc}
\hline Gender & Patient Group & Healthy Group \\
\hline Male & $41(41)$ & $41(41)$ \\
Female & $59(59)$ & $59(59)$ \\
\hline
\end{tabular}

a Data are presented as No. (\%).

Table 2. Distribution of Absolute and Relative Frequency of Subjects on the Basis of Nutritional Status and Physical Activity (2013-2014)

\begin{tabular}{|c|c|c|}
\hline & Patient Group & Healthy Group \\
\hline \multicolumn{3}{|l|}{ Number of meals } \\
\hline Two meals or less & $19(19)$ & $7(7)$ \\
\hline Three meals & $78(78)$ & $90(90)$ \\
\hline Four meals or more & $3(3)$ & $3(3)$ \\
\hline Total & 100 & 100 \\
\hline \multicolumn{3}{|l|}{ Food groups used } \\
\hline Breads and cereals & $68(41.22)$ & $50(23.58)$ \\
\hline Fruits & $15(9.09)$ & $43(20.28)$ \\
\hline Vegetables & $10(6.06)$ & $29(13.67)$ \\
\hline Milk and dairy products & $9(5.45)$ & $17(8.01)$ \\
\hline Meat, beans and nuts & $60(36.36)$ & $71(33.49)$ \\
\hline Fats and sugars & $3(1.81)$ & $2(.94)$ \\
\hline Total & $165(100)$ & $212(100)$ \\
\hline \multicolumn{3}{|l|}{ Use of special diets } \\
\hline Yes & $16(16)$ & $7(7)$ \\
\hline No & $84(84)$ & $93(93)$ \\
\hline Total & 100 & 100 \\
\hline \multicolumn{3}{|l|}{ Appetite } \\
\hline High appetite & $19(19)$ & $8(8)$ \\
\hline Normal & $69(69)$ & $84(84)$ \\
\hline Low appetite & $12(12)$ & $8(8)$ \\
\hline No appetite & $0(0)$ & $0(0)$ \\
\hline Total & 100 & 100 \\
\hline \multicolumn{3}{|l|}{ Vitamin Supplements } \\
\hline Vitamin C & $2(2)$ & $20(20)$ \\
\hline Vitamin D & $3(3)$ & $20(20)$ \\
\hline Vitamin E & $1(1)$ & $15(15)$ \\
\hline Vitamin C, D and E & $9(9)$ & $13(13)$ \\
\hline None & $85(85)$ & $32(32)$ \\
\hline Total & 100 & 100 \\
\hline \multicolumn{3}{|c|}{ Salad and vegetables consumption with meals } \\
\hline Yes, sometimes & $15(15)$ & $2(2)$ \\
\hline Yes, most of the time & $45(45)$ & $18(18)$ \\
\hline Yes, always & $40(40)$ & $80(80)$ \\
\hline Total & 100 & 100 \\
\hline \multicolumn{3}{|l|}{ How food was prepared } \\
\hline Boiled & $18(18)$ & $47(47)$ \\
\hline Fried & $36(36)$ & $10(10)$ \\
\hline
\end{tabular}


Agha Amiri Met al.

\begin{tabular}{|c|c|c|}
\hline Roasted & $14(14)$ & $12(12)$ \\
\hline All three forms & $32(32)$ & $31(31)$ \\
\hline Total & 100 & 100 \\
\hline \multicolumn{3}{|c|}{ Physical activity in the past } \\
\hline Very light & $9(9)$ & $12(12)$ \\
\hline Light & $6(6)$ & $28(28)$ \\
\hline Moderate & $27(27)$ & $43(43)$ \\
\hline Strenuous & $58(58)$ & $17(17)$ \\
\hline Total & 100 & 100 \\
\hline \multicolumn{3}{|c|}{ Physical activity in the present } \\
\hline Very light & $27(27)$ & $17(17)$ \\
\hline Light & $47(47)$ & $43(43)$ \\
\hline Moderate & $21(21)$ & $32(32)$ \\
\hline Strenuous & $5(5)$ & $8(8)$ \\
\hline Total & 100 & 100 \\
\hline \multicolumn{3}{|c|}{ History of walking in the past } \\
\hline Never & $28(28)$ & $18(18)$ \\
\hline Sometimes & $38(38)$ & $54(54)$ \\
\hline Always & $34(34)$ & $28(28)$ \\
\hline Total & 100 & 100 \\
\hline \multicolumn{3}{|c|}{ History of walking in the present } \\
\hline Never & $50(50)$ & $25(25)$ \\
\hline Sometimes & $31(31)$ & $47(47)$ \\
\hline Always & $19(19)$ & $28(28)$ \\
\hline Total & 100 & 100 \\
\hline \multicolumn{3}{|c|}{ Professional sports in the past } \\
\hline Yes & $32(32)$ & $29(29)$ \\
\hline No & $68(68)$ & $71(71)$ \\
\hline Total & 100 & 100 \\
\hline \multicolumn{3}{|c|}{ Professional sports in the present } \\
\hline Yes & $11(11)$ & $10(10)$ \\
\hline No & $89(89)$ & $90(90)$ \\
\hline Total & 100 & 100 \\
\hline \multicolumn{3}{|c|}{ Types of professional sport activity in the past } \\
\hline Physical fitness & $3(7.31)$ & $4(11.42)$ \\
\hline Aerobic & $2(4.87)$ & $2(5.71)$ \\
\hline Badminton & $1(2.43)$ & $1(2.85)$ \\
\hline Bodybuilding & $3(7.31)$ & $2(5.71)$ \\
\hline Basketball & $2(4.87)$ & $3(8.57)$ \\
\hline Boxing & $1(2.43)$ & $2(5.71)$ \\
\hline Discus throw & $1(2.43)$ & $1(2.85)$ \\
\hline Taekwondo & $3(7.31)$ & $2(5.71)$ \\
\hline Tennis & $2(4.87)$ & $1(2.85)$ \\
\hline TennisTennis & $1(2.43)$ & $1(2.85)$ \\
\hline Athletics & $1(2.43)$ & $1(2.85)$ \\
\hline Swimming & $2(4.87)$ & $6(17.14)$ \\
\hline Football & $6(14.63)$ & $4(11.42)$ \\
\hline Wrestling & $1(2.43)$ & $1(2.85)$ \\
\hline Volleyball & $1(2.43)$ & $2(5.71)$ \\
\hline Weightlifting & $11(26.82)$ & $4(11.42)$ \\
\hline Total & $41(100)$ & $35(100)$ \\
\hline
\end{tabular}

\section{Discussion}

At onset, symptoms and diseases relationship with aging is different for males and females. In this study, gender differences were observed regarding the relationship between knee osteoarthritis and aging. For females after the age of 50 years, the risk of knee osteoarthritis

increased per decade of age. However, in males the risk of disease increased after the age of 60 years.

In general, this study showed that the prevalence of knee osteoarthritis is different in males and females, according to age of onset, frequency of illness, weight and 
age; hormonal and other causes should be determined by future studies.

Lifestyle change is the core prevention strategy for osteoarthritis and with a suitable lifestyle and health the prevalence of the disease and its consequences on the patient, their family and community could be decreased (23).

This study showed that older age, female gender, lack of food consumption rich in vitamins and supplements, avoiding strenuous activity, walking in the past and professional sporting activities such as weightlifting and football influence the risk of osteoarthritis during middle and old age.

Kumar and colleagues claimed that the major risk factors for osteoarthritis include older age, female gender, obesity, difficult occupation, hard physical functions, genetic and racial factors, reduced consumption of vitamins in the body and smoking (24).

Self-care programs for osteoarthritis include physiotherapy, occupational therapy, movement and activities modification, and modification of functions that require bending and frequent use of joints. The effects of the disease on function and the patient quality of life, especially in elderly patients are ignored and this is a great challenge for the independence of the patients. The first step in health promotion and prevention of disease is knowing the risk factors (25).

Rates of primary hip and knee joint replacement are rising in many developed countries and with the increase in the average age of most populations they will probably continue to increase. For example, in England, rates of hip and knee replacement are higher in females compared with males, and rise steeply after the age of 60 years (26).

In our research, it was found that the percentage of people with knee osteoarthritis increased with age. This observation is similar to a study done in south Delhi (27) as well as a number of other studies $(28,29)$.

Black and Hooks suggested that a balanced diet helps maintain bone structure, muscles and joints. Consumption of foods rich in vitamins A and D, collagen synthesis, metabolism of bone and joint osteoarthritis and is effective for the prevention of infection. The study of Braunwald et al. (30) showed that women who have high physical activity during adolescence and middle age than those who are sedentary are at higher risk for developing osteoarthritis. The research done by Sudo and colleagues in 2008 , concluded that people with a previous history of heavy lifting and strenuous activity such as mining, driving and building are at increased risk of OA at an older age (31). Black and Hooks (32) claimed that activities of weight bearing such as regular and slow walking lead to increased joint mobility and strengthening of muscles, tendons and supportive ligaments of joints.

In our study, osteoarthritis was more prevalent in females than in males (59\% and $41 \%$, respectively). This difference is likely due to the lack of mobility, physical activity and social issues, especially in our region and higher prevalence of obesity among females in general. Iqbal et al.(33) reported that osteoarthritis was more prevalent in females (74\%) compared to males (26\%). A similar study also done by Sharma et al. (29) reported that the prevalence of OA was $70.1 \%$ in females and $41.6 \%$ in males.

In conclusion osteoarthritis is a major public health problem especially in the community after the age of 50 years. In our research, we observed that there is significant relationship between age, nutritional status, physical activity and knee osteoarthritis. Occupational knee bending, family history and history of knee injury were less prevalent in our research. The number of patients with knee osteoarthritis increases with aging; therefore, osteoarthritis may be prevented if preventive measures are taken at an earlier age.

The findings of this research provide valuable and useful information for clinical nurses regarding the causes of osteoarthritis. Therefore, when caring for these patients they will be more aware of these factors and provide necessary training for the patients. Also, the findings of this research can be beneficial in the field of education for nursing students. Also, the results of this research can used for scientific and job strengthening of the nursing.

\section{Acknowledgements}

We would like to appreciate the doctors and the patients who cooperated with us in this study. Financial support provided by the Research Council of the Ahvaz Branch of the Islamic Azad University, Ahvaz, Iran (research project grant) is gratefully acknowledged.

\section{Authors' Contributions}

Maryam Aghaamiri developed the original idea and the protocol, abstracted and analyzed the data, wrote the manuscript and was the guarantor. Abdolhassan Doulah contributed to the development of the protocol, abstracted the data and prepared the manuscript.

\section{Funding/Support}

Financial support was provided by the Research Council of the Ahvaz Branch of the Islamic Azad University, Ahvaz, Iran (research project grant).

\section{References}

1. Suri P, Morgenroth DC, Hunter DJ. Epidemiology of osteoarthritis and associated comorbidities. PM\&R. 2012;4(5):S10-9.

2. Hadler NM. Knee pain is the malady-not osteoarthritis. Ann Intern Med. 1992;116(7):598-9.

3. Guccione AA, Felson DT, Anderson JJ, Anthony JM, Zhang Y, Wilson PW, et al. The effects of specific medical conditions on the functional limitations of elders in the Framingham Study. Am J Public Health. 1994;84(3):351-8.

4. DeFrances CJ, Podgornik MN. 2004 National Hospital Discharge Survey. Adv Data. 2006(371):1-19.

5. Lawrence RC, Felson DT, Helmick CG, Arnold LM, Choi H, Deyo RA, et al. Estimates of the prevalence of arthritis and other rheumatic conditions in the United States. Part II. Arthritis Rheum. 2008;58(1):26-35. 
6. Kadam UT, Jordan K, Croft PR. Clinical comorbidity in patients with osteoarthritis: a case-control study of general practice consulters in England and Wales. Ann Rheum Dis. 2004;63(4):408-14.

7. Sellam J, Berenbaum F. The role of synovitis in pathophysiology and clinical symptoms of osteoarthritis. Nat Rev Rheumatol. 2010;6(11):625-35.

8. Felson DT, Zhang Y. An update on the epidemiology of knee and hip osteoarthritis with a view to prevention. Arthritis Rheum. 1998;41(8):1343-55.

9. Felson DT, Chaisson CE. Understanding the relationship between body weight and osteoarthritis. Baillieres Clin Rheumatol. 1997;11(4):671-81.

10. Oliveria SA, Felson DT, Cirillo PA, Reed JI, Walker AM. Body weight, body mass index, and incident symptomatic osteoarthritis of the hand, hip, and knee. Epidemiology. 1999;10(2):161-6.

11. World Health Organization.. Diet, nutrition, and the prevention of chronic diseases Report of a WHO Study Group. WHO Technical Report Series editor. Geneva; 1990.

12. Felson DT, Zhang Y. An update on the epidemiology of knee and hip osteoarthritis with a view to prevention. Arthritis Rheum. 1998;41(8):1343-55.

13. Srikanth VK, Fryer JL, Zhai G, Winzenberg TM, Hosmer D, Jones G. A meta-analysis of sex differences prevalence, incidence and severity of osteoarthritis. Osteoarthritis Cartilage. 2005;13(9):769-81.

14. McAlindon TE, Felson DT, Zhang Y, Hannan MT, Aliabadi P, Weissman B, et al. Relation of dietary intake and serum levels of vitamin D to progression of osteoarthritis of the knee among participants in the Framingham Study. Ann Intern Med. 1996;125(5):353-9.

15. Lohmander LS, Ostenberg A, Englund M, Roos H. High prevalence of knee osteoarthritis, pain, and functional limitations in female soccer players twelve years after anterior cruciate ligament injury. Arthritis Rheum. 2004;50(10):3145-52.

16. Roos EM, Ostenberg A, Roos H, Ekdahl C, Lohmander LS. Longterm outcome of meniscectomy: symptoms, function, and performance tests in patients with or without radiographic osteoarthritis compared to matched controls. Osteoarthritis Cartilage. 2001;9(4):316-24.

17. Puranen J, Ala-Ketola L, Peltokallio P, Saarela J. Running and primary osteoarthritis of the hip. Br Med J. 1975;2(5968):424-5.

18. Roos H, Lindberg H, Gardsell P, Lohmander LS, Wingstrand H. The prevalence of gonarthrosis and its relation to meniscectomy in former soccer players. Am J Sports Med. 1994;22(2):219-22.

19. McAlindon TE, Wilson PW, Aliabadi P, Weissman B, Felson DT. Level of physical activity and the risk of radiographic and symptomatic knee osteoarthritis in the elderly: the Framingham study. Am JMed.1999;106(2):151-7.

20. Mukuddem-Petersen J, Kruger HS. Association between stunting and overweight among 10-15-y-old children in the North West Province of South Africa: the THUSA BANA Study. Int J Obes Relat Metab Disord. 2004;28(7):842-51.

21. Philippaerts RM, Westerterp KR, Lefevre J. Doubly labelled water validation of three physical activity questionnaires. Int J Sports Med. 1999;20(5):284-9.

22. Brown JD. What issues affect Likert - Scale questionnaire formats? Shiken. 2000;4:18-21.

23. Roddy E, Doherty M. Changing life-styles and osteoarthritis: what is the evidence? Best Pract Res Clin Rheumatol. 2006;20(1):81-97.

24. Kumar dus S. Osteoarthritis: Research clinical . Rheumatol. 2008;22(4):657-75.

25. Williams F, Spe ctor T. Osteoarthritis. $J$ Rheumatol. 2007;126(2):364-8.

26. Dixon T, Shaw M, Ebrahim S, Dieppe P. Trends in hip and knee joint replacement: socioeconomic inequalities and projections of need.Ann Rheum Dis. 2004;63(7):825-30.

27. Salve H, Gupta V, Palanivel C, Yadav K, Singh B. Prevalence of knee osteoarthritis amongst perimenopausal women in an urban resettlement colony in South Delhi. Indian J Public Health. 2010;54(3):155-7.

28. Joshi K, Kumar R, Avasthi A. Morbidity profile and its relationship with disability and psychological distress among elderly people in Northern India. Int J Epidemiol. 2003;32(6):978-87.

29. Sharma MK, Swami HM, Bhatia V, Verma A, Bhatia SPS, Kaur G An epidemiological study of correlates of osteo-arthritis in geriatric population of UT Chandigarh. Indian J Community Med. 2007;32(1):77.

30. Braunwald E, Kasper DL, Fauci AS. Harrison's principles of internal medicine. 17th edNew York: MC Graw-hill; 2008.

31. Sudo A, Kanno M, Miharada K. J Orthopaedic Sci Springer Japan. 2008;13(5).

32. Black J, Hooks JH. [Medical-Surgical Nursing 2] Translated by Aatashzadeh,.Tehran: publishing community; 2005.

33. Iqbal MN, Haidri FR, Motiani B, Mannan A. Frequency of factors associated with knee osteoarthritis. J Pak Med Assoc. 2011;61(8):786-9. 